\title{
1 Physiological and genetic drivers underpinning canopy development are associated with 2 durum wheat yield in rainfed environments
}

3 Yichen Kang ${ }^{1}$, Shanice V. Haeften ${ }^{1}$, Daniela Bustos-Korts ${ }^{2}$, Stjepan Vukasovic ${ }^{3}$, Sana Ullah Khan ${ }^{1}$, 4 Jack Christopher ${ }^{4}$, Karine Chenu ${ }^{4}$, Jason A. Able ${ }^{5}$, Millicent R. Smith ${ }^{1,6}$, Kai P. Voss-Fels ${ }^{1}$, Andries B.

$5 \quad$ Potgieter $^{7}$, David R. Jordan ${ }^{8}$, Andrew K. Borrell ${ }^{8}$, Samir Alahmad ${ }^{1 *}$ and Lee T. Hickey ${ }^{1 *}$

$6 \quad{ }^{1}$ Centre for Crop Science, Queensland Alliance for Agriculture and Food Innovation, The University of

7 Queensland, Brisbane, QLD, Australia

$8 \quad{ }^{2}$ Biometris, Wageningen University and Research Centre, Wageningen, Netherlands

9 Institute of Agronomy and Plant Breeding, Justus Liebig University Giessen, Hesse, Germany

$10{ }^{4}$ Centre for Crop Science, Queensland Alliance for Agriculture and Food Innovation, The University of 11 Queensland, Toowoomba, QLD, Australia

$12{ }^{5}$ School of Agriculture, Food \& Wine, Waite Research Institute, The University of Adelaide, Urrbrae, 13 SA, Australia

$14{ }^{6}$ School of Agriculture and Food Sciences, Faculty of Science, The University of Queensland, Gatton, 15 QLD, Australia

$16{ }^{7}$ Centre for Crop Science, Queensland Alliance for Agriculture and Food Innovation, The University of 17 Queensland, Gatton, QLD, Australia.

$18{ }^{8}$ Centre for Crop Science, Queensland Alliance for Agriculture and Food Innovation, The University

19 of Queensland, Hermitage Research Facility, Warwick, QLD, Australia

$20 *$ *Correspondence: Samir Alahmad, s.alahmad@uq.edu.au 


\section{Abstract}

23 Durum wheat (Triticum turgidum L. ssp. Durum) is largely grown in rainfed production 24 systems around the world. New cultivars with improved adaptation to water-limited environments are required to sustain productivity in the face of climate change. Physiological traits related to canopy development underpin the production of biomass and yield, as they

27 interact with solar radiation and affect the timing of water use throughout the growing season.

28 Despite their importance, there is limited research on the relationship between canopy development and yield in durum wheat, in particular studies exploring temporal canopy

30 dynamics under field conditions. This study reports the genetic dissection of canopy development in a durum wheat nested-association mapping population evaluated for longitudinal normalized difference vegetation index (NDVI) measurements. Association mapping was performed to identify quantitative trait loci (QTL) for time-point NDVI and spline-smoothed NDVI trajectory traits. Yield effects associated with QTL for canopy development were explored using data from four rainfed field trials. Four QTL were associated with yield in specific environments, and notably, were not associated with a yield penalty in any environment. Alleles associated with slow canopy closure increased yield. This was likely due to a combined effect of optimised timing of water-use and pleiotropic effects on yield component traits, including spike number and spike length. Overall, this study suggests that slower canopy closure is beneficial for durum wheat production in rainfed environments.

41 Selection for traits or loci associated with canopy development may indirectly improve yield and support selection for more resilient and productive cultivars in water limited environments.

43 Keywords: association mapping, drought, marker-environment interaction, NDVI,

44 phenotyping, water stress 
45 Abbreviations

$\begin{array}{ll}\text { AUC } & \text { area under the curve } \\ \text { BLUE } & \text { best linear unbiased estimate } \\ \text { DAS } & \text { days after sowing } \\ \text { DTF } & \text { days to flowering } \\ \text { FDR } & \text { false discovery rate } \\ \text { FGCC } & \text { fractional green canopy cover } \\ \text { GS } & \text { Zadoks' growth stages } \\ \text { MTA } & \text { marker-trait associations } \\ \text { NAM } & \text { nested-association mapping } \\ \text { NDVI } & \text { normalised difference vegetation index } \\ \text { PC } & \text { principal component } \\ \text { PCA } & \text { principal component analysis } \\ \text { PH } & \text { plant height } \\ \text { QTL } & \text { quantitative trait loci } \\ \text { SE } & \text { stem elongation } \\ \text { SL } & \text { spike length } \\ \text { SN } & \text { spike number per unit area } \\ \text { SNP } & \text { single nucleotide polymorphism } \\ \text { SS } & \text { seedling stage } \\ \text { TL } & \text { tillering }\end{array}$




\section{Introduction}

Durum wheat, or pasta wheat (Triticum turgidum L. ssp. Durum; $2 \mathrm{n}=4 \mathrm{x}=28$ ) is an ancient food crop and an important industry in Mediterranean and sub-tropical agricultural regions (Sall et al., 2019). Production is often constrained by drought, during and post anthesis (Loss and Siddique, 1994). This can greatly reduce yield potential by limiting grain number and weight (Gevrek and Atasoy, 2012; Royo et al., 2000). Therefore, traits with phenotypic plasticity are important for increasing crop productivity, as trait plasticity allows for adaptive potential in response to environmental variations (Borrell et al., 2014; Maccaferri et al., 2008; Matesanz et al., 2020; Shavrukov et al., 2017). Traditionally, durum wheat breeders have selected for earlier flowering (Bassi and Nachit, 2019; De Vita et al., 2007; Miralles et al., 2002; Motzo et al., 2010) to minimise the impact of end-of-season drought on reproduction and grain-filling.

In addition to optimising flowering time, canopy traits associated with improved water use efficiency can be targeted. For instance, changes in canopy development (e.g., reduction in leaf size or tillering) provide an advantage under terminal drought conditions by shifting water use from pre- to post-anthesis (Borrell et al., 2014; George-Jaeggli et al., 2017). Limited transpiration rate at high evaporative demand can also conserve water for critical stages later in crop development (Collins et al., 2021). There is a fine balance between water supply and demand in crops and as such, the timing of water availability must be matched with phenological development. Although rapid canopy development can increase light interception (Regan et al., 1997) and reduce soil evaporation (Lopez-Castaneda et al., 1995), if there is insufficient stored soil moisture or in-crop rainfall, excessive canopy size may prematurely deplete soil water and exacerbate terminal drought (Nuttall et al., 2012). Thus, crop performance under drought conditions depends on complex source-sink dynamics between carbohydrate and water balance, where there are trade-offs between stress resilience and yield (Collins et al., 2021; Rodrigues et al., 2019). Given the dynamic nature of the environment, understanding canopy development may help to identify integrative traits that support yield.

Normalized difference vegetation index (NDVI) is used to characterise canopy attributes and is considered a good surrogate for biomass accumulation, canopy cover and plant vigour (Cabrera-Bosquet et al., 2011; Carlson and Ripley, 1997; Mullan and Reynolds, 2010; Xue and $\mathrm{Su}, 2017)$. NDVI, computed as the difference between near-infrared reflectance and red absorption divided by their sum, is influenced by leaf chlorophyll content and canopy 
architecture (Gamon et al., 1995). NDVI can be measured in a non-subjective and efficient manner which facilitates its use at the field level. The generalized NDVI profile captured during the growing season includes: (1) the green-up phase before canopy closure, also known as the exponential phase; (2) the peak canopy cover phase; and (3) the decline phase as leaves senesce (Brown and de Beurs, 2008; Masialeti et al., 2010; Smith et al., 1995; Soltani and Galeshi, 2002). Hereafter, the term canopy development refers to the green-up and maximum cover phases.

While many studies have used NDVI to characterize canopy dynamics during the senescence phase (Christopher et al., 2016; Christopher et al., 2014; Lopes and Reynolds, 2012; Pinto et $a l ., 2016)$, few have explored canopy development and assessed its impact on yield. In durum wheat, genetic studies have mapped quantitative trait loci (QTL) using NDVI captured at certain developmental stages or specific time-points (Condorelli et al., 2018; Shi et al., 2017). However, NDVI captured at a specific time point does not account for the temporal dynamics of canopy development. This is important to consider, as the correlation between NDVI captured at a specific time-point and yield is strongly dependent on the growth stage (Goodwin et al., 2018; Smith et al., 1995; Teal et al., 2006).

Alternatively, NDVI time-series data can be modelled, and features of the growth curve used to study the underlying genetics. In bread wheat and maize, longitudinal growth data has successfully captured trait development over time to reinforce QTL mapping power (Kwak et al., 2016; Lyra et al., 2020; Miao et al., 2020; Muraya et al., 2017). Different parameters of the growth curve related to the time period of interest, may be used to describe temporal NDVI dynamics, such as curve threshold values, inflection points and integrals (Bustos-Korts et al., 2019; Christopher et al., 2014; Lopes and Reynolds, 2012; Pinto et al., 2016). Considering the many environmental factors that can affect the canopy status, area under the respective curve summarises the cumulative changes and can provide a general assessment of canopy development. The approach is yet to be applied to study canopy development in durum wheat.

Understanding the genetics of adaptive traits like canopy development, and their interaction with the environment, is critical to support the development of new cultivars with improved adaptation (Hammer et al., 2020). Using a nested-association mapping population, we reveal the genetic components of canopy development in durum wheat. To gain biological and physiological insights into NDVI time-sequential data, we first explored relationships between NDVI, phenology, canopy cover and features of the growth curve. Secondly, we performed 
111 association mapping using both time-point NDVI and the area under the curve (AUC) for

112 NDVI. Finally, markers associated with canopy development were used in a linear mixed

113 model approach to investigate marker $\times$ environment interactions and yield effects across

114 multiple rainfed environments in Australia.

\section{Materials and methods}

\section{Plant materials and genotyping}

117 This study examined subsets of a durum wheat nested-association mapping (NAM) population 118 developed at The University of Queensland, as described by Alahmad et al. (2019). The NAM 119 population comprised 920 lines (10 families) generated by crossing eight elite lines from 120 ICARDA Morocco (i.e. Fastoz2, Fastoz3, Fastoz6, Fastoz7, Fastoz8, Fastoz10, Outrob4 and 121 Fadda98) as 'founders' to the Australian durum wheat cultivars Jandaroi and DBA Aurora, 122 which served as 'reference' varieties. The founder lines were used as donors for drought 123 adaptive attributes in durum wheat breeding programs in the Middle East and North Africa. 124 The reference varieties are preferred by the pasta industry for their quality and therefore widely 125 grown in Australia. The NAM population was genotyped using Diversity Arrays Technology 126 genotyping-by-sequencing single nucleotide polymorphism (SNP) markers (Alahmad et al., 127 2019). Allele coding used 0,1 , and 2 , where 0 is the reference allele homozygote, 1 is the SNP 128 allele homozygote and 2 is the heterozygote.

\section{Field trials}

130 A subset of the durum wheat NAM population and a selection of Australian durum wheat 131 varieties were evaluated in four rainfed field trials conducted in Australia between 2017 and 1322020 (Table 1), namely "2017_RW" at Roseworthy (34.30 $\left.{ }^{\circ} \mathrm{S} ; 138.41{ }^{\circ} \mathrm{E}\right)$, South Australia; 133 "2019_TS" at Tosari, near Tummaville (27.51 $\left.{ }^{\circ} \mathrm{S} ; 151.27^{\circ} \mathrm{E}\right)$, Queensland; and "2017_WW" 134 and "2020_WW" at Warwick (28.12 $\left.{ }^{\circ} \mathrm{S} ; 152.06^{\circ} \mathrm{E}\right)$, Queensland. The trials adopted partially 135 replicated row-column designs (Cullis et al., 2006), with the exception of 2017_RW which 136 used a randomized complete block design with three replicates. The total number of genotypes 137 ranged from 147 to 309 across the trials, with pairs of trials having between 51 and 146 138 genotypes in common. For all trials, starting fertilizer was applied at sowing so that nutrients 139 were not limited, and weeds and insects were controlled as required. Based on the nearest 
weather station to each trial site, weather information was acquired from the Bureau of Meteorology (http://www.bom.gov.au/) and the SILO database (Jeffrey et al., 2001).

142 To monitor soil moisture and estimate the impact of drought stress on yield in the 2020_WW

143 trial, two check genotypes (DBA Aurora and Fadda98) were sown in dryland and irrigated

144 blocks next to the main experiment. Both blocks were sown on the same day as the main trial.

145 The rainfed block was adjacent to 2020_WW and the irrigation block was adjacent to the 146 rainfed block (separated by buffer rows to prevent lateral movement of soil moisture across 147 treatments). Plot size was consistent with the main trial and each treatment was sown in a 148 completely randomized block design, using 12 replicates in the dryland treatment and 6 149 replicates in the irrigation treatment. About $20 \mathrm{~mm}$ of water was applied through drip tape 150 irrigation every 1-2 weeks to ensure a stress-free growing environment. To determine soil water 151 availability, soil water content was measured for both dryland and irrigated blocks at one week 152 pre-anthesis and at anthesis. In each strip, two soil cores were collected from DBA Aurora and 153 Fadda98 plots in both treatments. Each core was divided into $20 \mathrm{~cm}$ soil layers: 0-20, 20-40, 40-60, 60-80, 80-100, and 100-120 cm. A subsample from each soil layer was immediately weighed to obtain fresh weight, and then dried to a constant weight at $105^{\circ} \mathrm{C}$. Soil water content for each layer was calculated as [(fresh weight-dry weight)/dry weight $] \times 100 \%$.

\section{Data collection}

The 2020_WW trial was subjected to intensive canopy phenotyping and resulting phenotypes were used for association mapping. The trial comprised 309 genotypes evaluated using a p-rep design $(\sim 38 \%)$ of 456 plots $(6 \mathrm{~m} \times 1.05 \mathrm{~m}, 4$ rows) (Table 2$)$. NDVI data was captured for each plot every 1-2 weeks, specifically $22,29,36,43,50,63,70,78,85,91,99$ and 106 days after sowing (DAS) using a GreenSeeker ${ }^{\mathrm{TM}}$ handheld sensor (NTech Industries, Ukiah, CA, USA).

163 Measurements were recorded on sunny and still days, by holding the sensor at approximately

$1640.6 \mathrm{~m}$ height above the crop canopy of the central two rows while walking through the crop at a constant rate. Canopy cover images were also captured for all plots using a mobile phone camera (Apple iPhone10), at 29, 36, 43 and 50 DAS. The RGB images were processed using

167 Canopeo in the Matlab environment, for calculating fractional green canopy cover (FGCC) that 168 measures the canopy surface area (Patrignani and Ochsner, 2015). In each plot, the number of 169 spikes was manually recorded for an inner row (1 m length) to determine spike number per unit 170 area (SN) and spike length (SL) was recorded for six plants. Plant height (PH) of three random 171 plants in each plot was measured at maturity from ground to the top of the spike, excluding the 
awn length. Flowering time (DTF) was recorded as DAS to $50 \%$ flowering (Zadok's growth stage 65) of all plants in a plot (Zadoks et al., 1974). The crop was harvested using a smallplot machine harvester to obtain yield data.

To investigate the relationship between NDVI and crop developmental stages in the 2020_WW trial, a small panel of lines were selected for growth stage tracking from sowing to flag leaf emergence. The panel comprised 11 genotypes, which were selected based on divergent yield performance in previous rainfed yield trials (i.e., high yielding and low yielding lines). Each genotype was replicated 2-3 times in the trial (total 23 plots). Each plot was monitored for Zadoks' growth stages (GS) and 10 plants in the middle two rows of each plot were tagged for tracking tiller number until flag leaf emergence at 16, 22, 29, 36, 43, 50, 57, 63, 70, 78, and 85 DAS.

To investigate yield effects of SNPs associated with canopy development, analyses used yield data from the 2020_WW trial, plus data from the three other yield (2017_WW, 2017_RW and 2019_TS; Table 1). DTF was captured in all trials, except for 2017_RW (Table 1).

\section{Analysis of phenotypic data}

Spatial analyses were conducted for each trait to correct for spatial heterogeneity within each trial. A linear mixed model was fitted in ASReml-R to estimate adjusted genotype means (best linear unbiased estimates; BLUEs) for all traits in each trial as follows (Butler et al., 2009):

$$
y_{i j k m}=\mu+R e p_{m}+R_{j}+C_{k}+G_{i(m)}+e_{i j k(m)}
$$

where $y_{i j k m}$ denotes the plot observation of genotype $i$ in replicate $m$, row $j$ and column $k$, was modelled by fitting fixed effects for the overall mean $(\mu)$ and genotype $i\left(G_{i(m)}\right)$; and random effects for replicate $m\left(\operatorname{Rep}_{m}\right)$, row $j\left(R_{j}\right)$ and column $k\left(C_{k}\right)$; and $e_{i j k(m)}$ represents the vector of spatially correlated residuals. The variance components of $R_{j}, C_{k}$ and $e_{i j k(m)}$ were assumed to follow $R_{j} \sim N\left(0, \sigma_{r}^{2}\right), C_{k} \sim N\left(0, \sigma_{c}^{2}\right)$ and $e_{i j k(m)} \sim N\left(0\right.$, AR1 $\otimes$ AR1 $\left.\sigma^{2}\right)$, respectively. To correct for known or expected sources of variation that were suspected to have some effects on traits, the model was tested to assess the need for fitting of covariates (i.e., differences in establishment between genotypes, lodging). The covariates and random terms were evaluated with Wald chi-squared test and likelihood ratio test, respectively. The model was adjusted according to the identified significant terms at $\alpha=0.05$. Except for the replicate, non-significant 
201

202

203

204

205

206

207

208

209

210

211

212

213

214

215

216

217

218

219

220

221

222

223

224

225

226

227

228

model terms were dropped in an attempt to obtain the best fit. Slight modifications were made for analysing 2017_RW, where the residual term was modelled by a two-dimensional spatial model with correlation in row direction only.

Time-series modelling of canopy development used NDVI recorded from sowing to the peak of NDVI measures at 78 DAS (Fig. 1). To describe the trend of longitudinal BLUEs for NDVI, a smoothing spline was implemented in ASreml-R (Verbyla et al., 1999). To summarize the NDVI growth curve, AUC was calculated using the following formula:

$$
\mathrm{AUC}=\sum_{i=1}^{n}\left[\frac{N D V I_{(i+1)}+N D V I_{i}}{2}\right]\left[T_{(i+1)}-T_{i}\right]
$$

Where $N D V I_{i}$ is the NDVI prediction at the $i$ th DAS; $T_{i}$ is the $i^{\text {th }} \mathrm{DAS}$; and $n$ is the number of DAS of interest after i.

\section{Association mapping}

All data captured at the 2020_WW trial were used to perform association mapping. Genotype data was subjected to quality control, which excluded genotypes with $>20 \%$ missing marker information and markers with a call rate $<90 \%$ and a minor allele frequency $(\mathrm{MAF})<5 \%$.

Two different approaches were used to map QTL for canopy development. The first approach used BLUEs for NDVI at each time-point. The second approach used the AUC based on spline modelling of time series NDVI. Population structure was investigated using principal component analysis (PCA). An appropriate number of principal components (PCs) were determined by estimating the variances of PC scores. The retained PCs were included as covariates in association tests carried out with "FarmCPU" in R (Liu et al., 2016). The $p$-values of marker-trait associations (MTA) were adjusted in a multiple comparison procedure using false discovery rate (FDR) (Benjamini and Hochberg, 1995). Only associations with adjusted $p$-values ( $p$-FDR) less than 0.05 were considered as statistically significant and reported. For each QTL, the positive allele was determined as the allele associated with an increase in trait value. Data from each homozygous allele were tested for normality and homogeneity of variance. The means of genotypes carrying different homozygous alleles were statistically compared by independent t-tests. In several cases where data did not meet the normality criteria, non-parametric Wilcoxon rank sum test was performed to compare the allelic effect on traits. 
230 The marker $\times$ environment interaction $(\mathrm{M} \times \mathrm{E})$ was analysed with a linear mixed model, in a 231 multi-environment context using all four field trials (Table 1):

$$
y=\mu+E+M+M \times E+G+G \times L+G \times Y+e
$$

233

234

235

236

237

238

239

240

where $y$ is the vector of yield BLUEs; $\mu$ is the general mean; $E$ represents trial; $M$ denotes SNP; $M \times E$ is the interaction term between SNP and trial; $G$ is genotype; $G \times L$ is the genotype by location interaction; $G \times Y$ is the genotype by year interaction, and $e$ is the residual, assumed independent with identical distribution. In the model, $E, M$, and $M \times E$ were fixed effects, whereas $G, G \times L$ and $G \times Y$ were treated as random effects.

The SNP effect was modelled as the sum of a main effect common to all tested environments $(M)$, plus the interaction term representing environments-specific deviations $(M \times E)$. Since $M$ $\times E$ was tested conditional on the main effect, no attempt was made to interpret the SNP main effect when $\mathrm{M} \times \mathrm{E}$ is significant (Malosetti et al., 2013). When $\mathrm{M} \times \mathrm{E}$ is not significant, the SNP main effect could be sufficient to represent the SNP effect. After testing, only SNPs with either significant main effect or $\mathrm{M} \times \mathrm{E}$ effects were reported and further investigated. The predicted means of each SNP allele $\times$ trial combination were compared with Tukey's HSD test.

A summary of the key steps and workflow involved from modelling NDVI time series data to the $\mathrm{M} \times \mathrm{E}$ analysis is provided in Fig. 2 .

\section{Results}

\section{Field environments experienced variable rainfall patterns}

The amount of in-crop rainfall varied across the four trials, ranging from $12.8 \mathrm{~mm}$ (2019_TS) to $320.7 \mathrm{~mm}$ (2017_RW). While 2019_TS received the least in-crop rainfall (only $12.8 \mathrm{~mm}$ ) the trial was sown into a full soil profile and the soil is described as deep with high waterholding capacity. This delayed water stress until the grain filling period and the site recorded the lowest mean yield (2.24 tonnes $\mathrm{ha}^{-1}$ ) in comparison with other trials (Fig. S4C, Table 1). The distribution of rainfall through the season also varied across the trials (Fig. S4). For example, 2017_RW experienced a typical Mediterranean-type environment, where most rainfall occurred early in the season. In contrast, the two trials conducted at Warwick received 
more rainfall during the critical grain filling period (Fig. S4B, D). The highest average yield was obtained in 2017_WW, which was on average 1 tonne ha ${ }^{-1}$ higher than 2017_RW and 2020_WW, and 2.7 tonnes ha ${ }^{-1}$ higher than 2019_TS (Table 1).

To quantify the degree of water stress in the 2020_WW canopy phenotyping trial, soil cores were sampled from dryland and irrigated strips adjacent to the main trial. Sampling performed one week prior to anthesis revealed significant differences in soil moisture (all soil depths from $0-1.2 \mathrm{~m}$ ) for the dryland treatment compared to the irrigated treatment (Fig. S7A). At anthesis, soil moisture was further depleted, particularly at depth (Fig. S7A). DBA Aurora and Fadda98 obtained significantly higher yield in the irrigated treatment (Fig. S7B). Based on average yield differences between dryland and irrigated treatments, the degree of water stress experienced in the 2020_WW trial resulted in an approximate average yield loss of 1.1 tonnes ha $^{-1}$.

\section{Relationships between NDVI, phenology traits and yield-related traits}

The 309 NAM genotypes evaluated in 2020_WW trial displayed a high degree of phenotypic variation for temporal NDVI (Fig. 1). Phenotypic variation in NDVI was largest at the beginning of the growing season, reached a peak at 36 DAS and reduced thereafter. The NDVI reached an average peak value of 0.9 at 78 DAS (Table 3). The Pearson correlation among all traits was computed (Fig. 3). For a specific time-point NDVI, its correlations with other timepoints decreased with increasing developmental stage. Positive correlations between NDVI and SL were significant at 29 and 78 DAS $(p<0.05)$. A reverse trend was observed for SN, where NDVI in the early season (22 and 29 DAS) was negatively correlated with SN. For plant height, the only correlation with NDVI was evident at 50 DAS $(p<0.05)$. Further, NDVI captured over time was negatively correlated with DTF (Fig. 3), with higher NDVI associated with faster time to flowering. No direct NDVI-yield relationship was found before 63 DAS in our study. Rather, NDVI recorded closer to flowering time was more highly related to final yield, as the strongest correlation between NDVI and yield was observed at 78 DAS $(p<0.001)$.

\section{Modelling NDVI over time to estimate growth stages}

The longitudinal data fitted with a spline showed that the NDVI growth curves overall, increased slowly initially, then rapidly, before reaching a final plateau (Fig. 4). This suggested three different growth phases likely involved in canopy development in durum wheat. Although the trends of these curves were more or less in parallel over time, the distribution of genotypespecific NDVI trajectories indicated some heterogeneity in each phase, leading to variation in 
phase-specific AUC traits. For this reason, the entire simulated AUC during the vegetative stage (AUC_VS) could be divided into three phases, each illustrating a different growth status, to capture phase-specific variation that contributes to the overall canopy development.

To understand how NDVI dynamics reflected changes in vegetation phenology, 11 genotypes including 10 NAM lines and the reference variety DBA Aurora were investigated. Given the similar phenology of the 11 genotypes, Zadok's GS20 (start of tillering) and GS31 (first node) were aligned with 29 and 63 DAS (Fig. S1), respectively. Since no significant change was observed for the tiller number of most genotypes from 57-63 DAS (Fig. S1), Zadok's GS30 (start of stem elongation) was estimated at 60 DAS. To evaluate the use of NDVI to define the growth stage, we hereafter used 30 and 60 DAS as two breakpoints to approximate GS20 and GS30, respectively.

Using 30 DAS as the first breakpoint, the NDVI trajectories of genotypes displayed two distinct growth patterns before and after the point. For instance, the sharp increase in NDVI after 30 DAS suggested a transition from seedling to tillering stage. According to the fitted NDVI curves, most genotypes reached the start of maximum canopy cover at approximately 60 DAS (Fig. 4). This finding aligned with the start of the maximum canopy cover as indicated by timepoint NDVI measures (Fig. 1), where NDVI after 63 DAS remained constant. As such, the estimated transition from tillering to stem elongation by the NDVI curve was deemed reasonably accurate. However, to further identify and interpret phenology metrics, the saturation issue may impact NDVI-based recommendations as NDVI becomes insensitive to changes in canopy structure when the crop reaches canopy closure.

\section{The relationship between time-point NDVI and AUC traits}

NDVI curves were binned into three growth stages: seedling stage (SS, 0-30 DAS), tillering stage (TL, 30-60 DAS) and stem elongation stage (SE, 60-78 DAS) (Fig. 4). Accordingly, the AUC traits for each stage were designated AUC_SS, AUC_TL and AUC_SE, and were used to quantify the cumulative status for each stage. Given this, the same duration of each growth stage was applied to all studied genotypes. Hence, differences in growth rate appeared to contribute to variation in AUC, where higher AUC values represented faster canopy development and closure. 
317 As expected, because of the linear nature of the operations involved, stage-specific AUC traits

318 showed strong correlations with NDVI measured within the respective stage (Fig. 3). Moreover,

319 stage-specific AUC traits were also found to correlate well with NDVI measured at other stages.

320 The integral NDVI approach ensured that canopy differences related to yield formation were

321 captured. For example, AUC_SE was correlated with yield, but only some of the NDVI time-

322 points during SE showed significant correlations with yield (e.g., 70 DAS was not correlated,

323 but readings captured at 63 DAS and 78 DAS were, as shown in Fig. 3). These results

324 highlighted the robustness and suitability of the approach for proceeding with genetic

325 dissection studies.

\section{Time-point NDVI and AUC correlate with canopy cover}

NDVI displayed a positive linear relationship with FGCC before NDVI reached the maximum value of 0.9 (Fig. 5). Most genotypes obtained 80\% FGCC at 50 DAS. Thus, rapid growth during the tillering stage could almost achieve canopy closure before the start of stem elongation. Moreover, all AUC traits showed significant correlations with FGCC, except for AUC_SS (Fig. 3). This highlights the value of NDVI to estimate canopy cover as measures were similar to RGB-based estimates. As such, a higher NDVI and/or a greater AUC value represented a larger canopy that was faster to close.

\section{Association mapping for canopy development}

A total of 5,298 high-quality polymorphic SNP markers for 309 lines were used for association mapping. The PCA revealed six clusters in the NAM population (Fig. S2A), which aligned with the family structure (Table 2). The first five PCs were used as covariates in association mapping, because explained variance rapidly decreased until $\mathrm{PC}=5$ and changed little thereafter (Fig. S2B). The first two PCs explained $~ 23 \%$ of the genetic variance (Fig. S2B).

Association mapping was performed for time-point NDVI, stage-based AUC, crop phenologyrelated traits, spike traits and grain yield traits captured in the 2020_WW trial. Using timepoint NDVI, a total of 11 significant MTAs were detected across nine chromosomes, including 2A, 2B, 3A, 4A, 4B, 5A, 6A, 6B and 7A (Table 4). Among these, only one SNP was detected for more than one NDVI time-point (i.e., SNP 1271404 on chromosome 2A). Notably, in agreement with the genetic variation in NDVI (Fig. 1), most MTAs were identified at specific time-points between 29 and 50 DAS. 
347 To identify markers associated with AUC, we conducted association mapping using the 348 following traits: AUC_SS, AUC_TL, AUC_SE and AUC_VS. This detected six significant 349 MTAs, of which five were associated with more than one AUC trait. SNP 1271404 on

350 chromosome 2A, was also detected using time-point NDVI measures during the TL growth 351 stage. Mapping AUC enabled the identification of five additional signals, on chromosome 2A 352 (SNP 4004899), 2B (SNPs 1095539 and 1108975), 4A (SNP 3946360) and 5B (SNP 1093322) 353 (Table 4).

354 Interestingly, most MTAs for phenology-related traits were independent of MTAs associated with canopy development, except for SNP 2256343 on chromosome 2A which was associated with NDVI_50DAS and DTF (Table 4).

\section{$\mathbf{M} \times \mathbf{E}$ analysis revealed markers associated with grain yield}

The $\mathrm{M} \times \mathrm{E}$ interaction analysis was conducted to assess the significance and strength of the SNP effects on yield across trials. Analyses focussed on 13 SNPs that were associated with canopy development and segregating in population subsets evaluated across all trials.

361 The allelic effects on canopy development were first explored using data collected from

362 2020_WW. For all SNPs, the allele associated with either higher NDVI or larger AUC was defined as the positive allele, which was linked to rapid canopy closure (Table 4). To account for the fact that SNP 2256343 was also associated with flowering time (Fig. S3, Table 4), we excluded the top $20 \%$ and bottom $20 \%$ of genotypes in 2019_TS and 2020_WW based on DTF. As a result, 131 and 185 genotypes that showed no significant difference in DTF were retained in 2019_TS and 2020_WW, respectively, and were used for the analysis of yield effects associated with SNP 2256343.

A linear mixed model approach was employed to evaluate effects for each of the 13 SNPs using yield data from four rainfed trials (Table 1). In the current study, no significant marker main effect was detected for yield. Instead, 9 markers showed significant $\mathrm{M} \times \mathrm{E}$ interactions for yield (Table 5). Notably, SNP 1095539, 3949783, 4404447 and 5324123 showed significant yield effects in 2017_WW, 2017_WW, 2017_RW, and 2020_WW, respectively (Table 5). Alleles associated with a significant yield benefit were associated with slow canopy closure (Fig. S5; Table 4, 5). Therefore, these four SNPs of interest were subjected to further investigation. 
Alleles influencing canopy development and yield were also associated with spike length and spike number

Three of the four marker alleles associated with a slower closing canopy and yield (1095539, 3949783, 4404447 and 5324123) also showed associations with SL or SN. Interestingly, SNP 5324123 was strongly associated with both SL and SN in 2020_WW, but the yield benefit in this trial was related to a reduction in SN (Fig. S6D, Table 5-6). Similarly, the significant yield effect of SNP 1095539 in 2017_WW was associated with SL (Fig. S6D, Tables 5-6). On the other hand, SNP 3949783 was associated with SL in 2020_WW but not yield (Tables 5-6). SNP 4404447 was not associated with either component traits (Table 6). Notably, SNP 4404447 was not associated with yield in 2017_WW and 2020_WW and these were the environments where data for SL and SN were captured (Table 5). Overall, alleles associated with slow canopy closure supported yield, however, the contribution and yield benefit associated with pleiotropic effects on SL and SN appeared highly context dependent across the environments.

\section{Discussion}

Wheat yield is determined by the interaction between source, which is the availability of photoassimilates, and sink, which is the number of grains per unit area (Reynolds et al., 2017). Canopy development underpins yield potential, as it influences the capture of light, water use, transpiration, and overall biomass production. In water-limited environments, optimal canopy development balances water use both pre- and post-anthesis to maximise yield. For example, while slow canopy development may not favour biomass accumulation pre-anthesis, it can help to conserve soil moisture for the critical grain filling period. However, in environments where water is non-limiting, optimal canopy development should maximise biomass production and overall sink strength as there is no penalty of high water-use early in the season. This study revealed a high degree of variation for temporal canopy dynamics in elite durum wheat populations derived from Australian $\times$ ICARDA crosses, which could be used to improve durum wheat adaptation to a range of target environments. New knowledge of the underlying genetics and value of canopy developmental traits described in this study provide important maximise crop yield. 
407 NDVI serves as an easy-to-measure indicator of canopy development in real time. The link 408 between NDVI and canopy development is strongly underpinned by the functional relationship 409 between NDVI and aboveground biomass. In accordance with previous research, time-specific 410 NDVI measures during the early growing period were generally poor predictors of yield

411 (Magney et al., 2016), whereas NDVI captured at the peak of canopy development is more 412 associated with yield. This is somewhat expected due to the complexity underpinning yield 413 development. Furthermore, the stem elongation to flowering phase is considered the most 414 critical for determining grain number and ultimately sink strength.

415 Phenological and environmental changes over time affect the canopy status represented by 416 NDVI. Therefore, the use of the NDVI integral (i.e., area under the curve) provides an 417 advantage over time specific NDVI as it captures the impact of those changes on canopy 418 development. To accurately assess long-term patterns of canopy development, regular NDVI measurements are required. Nonlinear models have been widely used to account for the complexities of plant growth (Paine et al., 2012; Villegas et al., 2001). Previous studies comparing different models to characterise the dynamics of NDVI over time found that splinefitting better approximated the variation of smoothed NDVI values than other non-linear functions and was more suitable for describing the time-series model (Sun et al., 2017; Vorobiova and Chernov, 2017). In this study, the trajectories of smoothed NDVI data showed a typical temporal pattern of NDVI evolution during the vegetative stage, where crop emergence was followed by a rapid growth period, then a relatively stable period of maximum vegetation approaching anthesis. Therefore, cumulative NDVI at specific growth stages could be used to gain insights of the physiological drivers underpinning grain yield.

\section{The genetics of canopy development}

430 To identify loci underpinning canopy development, time-point NDVI data were treated as 431 independent traits and association mapping was performed for each timepoint to identify time432 specific NDVI (Fig. 2). Next, spline-fitted curve-derived AUC was subject to mapping, and results were compared to mapping of time-point NDVI.

434 Time-point NDVI measures were highly correlated, suggesting the underlying genetic controls 435 either provide long-term regulation of canopy growth or have prolonged effects originating 436 from an early growth phase. This was further confirmed in the mapping results, where the $2 \mathrm{~A}$ 437 QTL (SNP 1271404) was detected by multiple time-point NDVI. 
AUC in the current study was used to capture the genetic basis of canopy growth with respect to key developmental stages. However, some QTL could only be detected using time-point NDVI and it is unclear why these QTL could not be captured using the AUC approach. One possible explanation is that they were transient QTL sensitive to time of data collection, whereas AUC represented a period of growth, and therefore more likely detected loci with more consistent and robust effects. Thus, time-point NDVI and AUC had different mapping strengths and were complementary to each other. The use of AUC for mapping time-dependent canopy development should be implemented on a case-by-case basis, with the aim of ensuring good quality data for use in modelling canopy dynamics. Additionally, AUC values should not be directly compared across different studies, as AUC is a product of many contributing factors, including the environment, modelling approach, phenotyping method and crop phenology.

This study uncovered four SNPs on chromosomes 2B (1095539 and 3949783), 4A (5324123) and 6A (4404447) that could be useful for durum wheat breeding, as alleles associated with slow canopy closure were linked to a yield advantage in some environments, but not a yield penalty in other environments. Notably, all four SNPs were not associated with DTF, which improves the utility of the genes from a breeding perspective, as canopy development could be manipulated without shifting flowering time. Three of the four SNPs (1095539, 3949783 and 5324123) were also associated with yield component traits: SN and SL, where SL is considered a proxy for the number of grains per spike (Baye et al., 2020). Interestingly, most of these SNPs were detected using NDVI measures recorded at the early tillering stage, an important phase for spike formation in wheat (Khadka et al., 2020), when no correlation between NDVI and yield was found. The 2B (3949783) and 6A (4404447) regions have previously been reported to influence a range of spike traits including spike dry matter, grain weight per spike, grains per spike and grain weight (Giunta et al., 2018; Mangini et al., 2018; Patil et al., 2013; Peleg et al., 2009; Soriano et al., 2017). While the 4A region (5324123) has not previously been reported for SN and SL per se, it has been reported to influence similar or related traits, including biomass, harvest index, spike harvest index, spike density (spikelet number/SL), and importantly grain yield (Mengistu et al., 2016; Peleg et al., 2011; Peleg et al., 2009; Tzarfati et al., 2014).

\section{Yield benefits of slow canopy development, trade-offs and pleiotropic effects}

Four QTL for slow canopy development were associated with yield in three of the four rainfed environments (2017_RW, 2017_WW and 2020_WW). These three trials likely experienced 
water stress at anthesis, whereas 2019_TS received very little in-crop rainfall (Fig. S4C) and likely experienced pre-anthesis water stress. This highlights the value of slow canopy development in water-limited environments that experience drought at anthesis or during the grain filling period. As discussed above, the benefit of a slow closing canopy likely manifests from water savings that support yield formation during grain filling. Without having sufficient environmental data to perform robust envirotyping in APSIM (Chenu et al., 2013), it is difficult to quantify the degree of water-stress in the rainfed experiments. However, soil moisture was measured in the dryland and irrigated strips adjacent to the 2020_WW trial. Soil moisture under the rainfed conditions was clearly depleted at anthesis, particularly in deeper soil layers (Fig. $\mathrm{S} 7 \mathrm{~A}$ ), and the water limitation resulted in an average yield loss of 1.1 tonnes $\mathrm{ha}^{-1}$. This highlights the impact of drought under rainfed conditions in Australia, despite three of the four trials being conducted on deep soils with a high water-holding capacity. Although soil moisture data was not available for 2017_WW, the same site was used for 2020_WW. In 2017_WW the trial received less in-crop rainfall compared to 2020_WW (Table 1), suggesting it likely experienced similar or more severe water stress than 2020_WW. Terminal drought often occurs in Mediterranean-type environments, such as South Australia. In 2017_RW, about 90\% of the in-crop rainfall occurred from May to September, suggesting the trial experienced water stress late in the season (Fig. S4A). Regardless of the delayed onset of water stress (compared with the Warwick sites in Queensland), the four QTL associated with slow canopy development contributed positive yield effects.

Harvested wheat yield is a result of three components: spike number per unit area, grain number per spike, and average grain weight (Simmonds et al., 2014; Zhang et al., 2018). In the current study, the relationship between SL, SN and yield varied across the two trials (2017_WW and 2020_WW). Specifically, SL showed a significant correlation with yield in 2017_WW, but not in 2020_WW (Fig. S6A, C), while SN showed a significant correlation with yield in 2020_WW, but not in 2017_WW (Fig. S6B, D). Previous studies in both bread and durum wheat have reported positive relationships between SL and yield under water-limited conditions (Munir et al., 2007; Nofouzi, 2018). In this scenario, genotypes with fewer tillers could accumulate less biomass, but produce longer spikes with more grains, to achieve a yield advantage.

It is plausible that loci associated with canopy development and yield component traits could be involved in modulating root architecture. The study by Voss-Fels et al. (2018) reported that allelic variation at $\operatorname{Vrnl}$, a key gene in the wheat flowering pathway, not only influences spike 
502 and canopy development, but also root system architecture. In the current study, a QTL on 2B 503 (1095539) associated with AUC_SS and AUC_SE was positioned in close proximity with 504 previously reported QTL for root growth angle and primary root length (Maccaferri et al., 505 2016). Thus, either closely positioned or pleiotropic loci on chromosome $2 \mathrm{~B}$ could be important 506 for both above- and below-ground developmental traits.

507 Clearly, the value of different yield component traits in durum wheat is highly context 508 dependent, and genotypes can exploit a range of pathways to maximise yield in each environment. A priority for future research is to understand the complex interactions and 510 possible pleiotropic effects of loci influencing both canopy development and yield component

511 traits. Such insight will enable selection and deployment of desirable gene combinations in

512 breeding programs seeking to develop new varieties with improved resilience and productivity.

\section{Acknowledgements}

514 Funding was supported by Grain Research and Development Corporation (GRDC; project code 515 UOQ1903-007RTX).

\section{Author Contribution}

517 YCK, LTH and SA conceived and designed the study. SUK and SA contributed to developing 518 the plant materials. YCK, SA, JA and LTH performed the phenotyping. SV processed RGB 519 images using Canopeo. YCK analysed the data. YCK and SVH prepared the figures. DBK and $520 \mathrm{KPV}$ advised on the data analysis. KC and JC advised on interpretation of trait relationships. 521 YCK wrote the manuscript. AKB contributed to physiological understanding of the data, DBK, 522 AKB, MRS and LTH edited the manuscript. All authors read and reviewed the manuscript.

\section{Data Availability Statement}

524 All data supporting the findings of this study are available within the paper and within its supplementary materials published online.

\section{References}

527 Alahmad S, El Hassouni K, Bassi FM, Dinglasan E, Youssef C, Quarry G, Aksoy A, 528 Mazzucotelli E, Juhasz A, Able JA, Christopher J, Voss-Fels KP, Hickey LT. 2019. A major 529 root architecture QTL responding to water limitation in durum wheat. Frontiers in Plant 530 Science 10. 
531 Bassi FM, Nachit MM. 2019. Genetic gain for yield and allelic diversity over 35 years of durum

532 wheat breeding at ICARDA. Crop Breed. Genet. Genom 1, 1-19.

533 Baye A, Berihun B, Bantayehu M, Derebe B. 2020. Genotypic and phenotypic correlation and

534 path coefficient analysis for yield and yield-related traits in advanced bread wheat (Triticum

535 aestivum L.) lines. Cogent Food \& Agriculture 6.

536 Benjamini Y, Hochberg Y. 1995. Controlling the False Discovery Rate: A Practical and Powerful Approach to Multiple Testing. Journal of the Royal Statistical Society Series BStatistical Methodology 57, 289-300.

539 Borrell AK, Mullet JE, George-Jaeggli B, van Oosterom EJ, Hammer GL, Klein PE, Jordan 540 DR. 2014. Drought adaptation of stay-green sorghum is associated with canopy development, 541 leaf anatomy, root growth, and water uptake. Journal of Experimental Botany 65, 6251-6263.

542 Brown ME, de Beurs KM. 2008. Evaluation of multi-sensor semi-arid crop season parameters 543 based on NDVI and rainfall. Remote Sensing of Environment 112, 2261-2271.

544 Bustos-Korts D, Boer MP, Malosetti M, Chapman S, Chenu K, Zheng BY, van Eeuwijk F. 545 2019. Combining Crop Growth Modeling and Statistical Genetic Modeling to Evaluate 546 Phenotyping Strategies. Frontiers in Plant Science 10.

547 Butler DG, Cullis BR, Gilmour AR, Gogel BJ. 2009. ASReml-R reference manual. The State of Queensland, Department of Primary Industries and Fisheries, Brisbane.

550 potential tool for predicting biomass, plant nitrogen content and growth in wheat genotypes 551 subjected to different water and nitrogen conditions. Cereal Research Communications 39, 552 147-159.

553 Carlson TN, Ripley DA. 1997. On the relation between NDVI, fractional vegetation cover, and leaf area index. Remote Sensing of Environment 62, 241-252.

Chenu K, Deihimfard R, Chapman SC. 2013. Large-scale characterization of drought pattern: a continent-wide modelling approach applied to the Australian wheatbelt spatial and temporal trends. New Phytologist 198, 801-820.

Christopher JT, Christopher MJ, Borrell AK, Fletcher S, Chenu K. 2016. Stay-green traits to improve wheat adaptation in well-watered and water-limited environments. Journal of 560 Experimental Botany 67, 5159-5172.

561 Christopher JT, Veyradier M, Borrell AK, Harvey G, Fletcher S, Chenu K. 2014. Phenotyping 562 novel stay-green traits to capture genetic variation in senescence dynamics. Functional Plant 563 Biology 41, 1035-1048.

564 Collins B, Chapman S, Hammer G, Chenu K. 2021. Limiting transpiration rate in high evaporative demand conditions to improve Australian wheat productivity. in silico Plants 3, diab006.

Condorelli GE, Maccaferri M, Newcomb M, Andrade-Sanchez P, White JW, French AN, Sciara G, Ward R, Tuberosa R. 2018. Comparative aerial and ground based high throughput phenotyping for the genetic dissection of NDVI as a proxy for drought adaptive traits in durum wheat. Frontiers in Plant Science 9.

571 Cullis BR, Smith AB, Coombes NE. 2006. On the design of early generation variety trials with 572 correlated data. Journal of Agricultural Biological and Environmental Statistics 11, 381-393.

573 De Vita P, Nicosia OL, Nigro F, Platani C, Riefolo C, Di Fonzo N, Cattivelli L. 2007. Breeding 574 progress in morpho-physiological, agronomical and qualitative traits of durum wheat cultivars released in Italy during the 20th century. European Journal of Agronomy 26, 39-53.

Gamon JA, Field CB, Goulden ML, Griffin KL, Hartley AE, Joel G, Peñuelas J, Valentini R. 1995. Relationships between NDVI, canopy structure, and photosynthesis in three Californian vegetation types. Ecological Applications 5, 28-41. 
George-Jaeggli B, Mortlock MY, Borrell AK. 2017. Bigger is not always better: Reducing leaf area helps stay-green sorghum use soil water more slowly. Environmental and Experimental Botany 138, 119-129. Gevrek MN, Atasoy GD. 2012. Effect of post anthesis drought on certain agronomical characteristics of wheat under two different nitrogen application conditions. Turkish Journal of Field Crops 17, 19-23. Variation for Yield-Related Traits of Durum Wheat as Affected by Development. Frontiers in Plant Science 9.

588 Goodwin AW, Lindsey LE, Harrison SK, Paul PA. 2018. Estimating Wheat Yield with 589 Normalized Difference Vegetation Index and Fractional Green Canopy Cover. Crop Forage \& 590 Turfgrass Management 4.

591 Hammer GL, McLean G, van Oosterom E, Chapman S, Zheng BY, Wu A, Doherty A, Jordan D. 2020. Designing crops for adaptation to the drought and high-temperature risks anticipated in future climates. Crop Science 60, 605-621.

Jeffrey SJ, Carter JO, Moodie KB, Beswick AR. 2001. Using spatial interpolation to construct a comprehensive archive of Australian climate data. Environmental Modelling \& Software 16, 309-330.

Khadka K, Earl HJ, Raizada MN, Navabi A. 2020. A Physio-Morphological Trait-Based Approach for Breeding Drought Tolerant Wheat. Frontiers in Plant Science 11.

599 Kwak IY, Moore CR, Spalding EP, Broman KW. 2016. Mapping uantitative trait loci 600 underlying function-valued traits using functional principal component analysis and multi-trait mapping. G3-Genes Genomes Genetics 6, 79-86.

603 Liu XL, Huang M, Fan B, Buckler ES, Zhang ZW. 2016. Iterative Usage of Fixed and Random Effect Models for Powerful and Efficient Genome-Wide Association Studies. Plos Genetics 12.

604

605

606 Lopes MS, Reynolds MP. 2012. Stay-green in spring wheat can be determined by spectral reflectance measurements (normalized difference vegetation index) independently from phenology. Journal of Experimental Botany 63, 3789-3798.

607 Lopez-Castaneda C, Richards RA, Farquhar GD. 1995. Variation in early vigor between wheat 608 and barley. Crop Science 35, 472-479.

609 Loss SP, Siddique KHM. 1994. Morphological and physiological traits associated with wheat 610 yield increases in Mediterranean environments. Advances in Agronomy, Vol 52 52, 229-276.

611 Lyra DH, Virlet N, Sadeghi-Tehran P, Hassall KL, Wingen LU, Orford S, Griffiths S, 612 Hawkesford MJ, Slavov GT. 2020. Functional QTL mapping and genomic prediction of 613 canopy height in wheat measured using a robotic field phenotyping platform. Journal of 614 Experimental Botany 71, 1885-1898.

615 Maccaferri M, El-Feki W, Nazemi G, Salvi S, Cane MA, Colalongo MC, Stefanelli S, Tuberosa 616 R. 2016. Prioritizing quantitative trait loci for root system architecture in tetraploid wheat. 617 Journal of Experimental Botany 67, 1161-1178.

618 Maccaferri M, Sanguineti MC, Corneti S, Ortega JLA, Ben Salem M, Bort J, DeAmbrogio E, 619 del Moral LFG, Demontis A, El-Ahmed A, Maalouf F, Machlab H, Martos V, Moragues M, 620 Motawaj J, Nachit M, Nserallah N, Ouabbou H, Royo C, Slama A, Tuberosa R. 2008. 621 Quantitative trait loci for grain yield and adaptation of durum wheat (Triticum durum Desf.) across a wide range of water availability. Genetics 178, 489-511.

Magney TS, Eitel JUH, Huggins DR, Vierling LA. 2016. Proximal NDVI derived phenology improves in-season predictions of wheat quantity and quality. Agricultural and Forest Meteorology 217, 46-60. data: modeling genotype-by-environment interaction and its genetic basis. Frontiers in Physiology 4. 

Mastrangelo AM, Laido G, Pecchioni N, Blanco A. 2018. Genetic dissection of the relationships between grain yield components by genome-wide association mapping in a collection of tetraploid wheats. Plos One 13.

633 Masialeti I, Egbert S, Wardlow BD. 2010. A Comparative Analysis of Phenological Curves for Major Crops in Kansas. Giscience \& Remote Sensing 47, 241-259. Matesanz S, Ramos-Munoz M, Moncalvillo B, Teso MLR, de Dionisio SLG, Romero J, Iriondo JM. 2020. Plasticity to drought and ecotypic differentiation in populations of a crop wild relative. Aob Plants 12.

638 Mengistu DK, Kidane YG, Catellani M, Frascaroli E, Fadda C, Pe ME, Dell'Acqua M. 2016. 639 High-density molecular characterization and association mapping in Ethiopian durum wheat 640 landraces reveals high diversity and potential for wheat breeding. Plant Biotechnology Journal 641 14, 1800-1812.

642 Miao C, Xu Y, Liu S, Schnable PS, Schnable JC. 2020. Increased power and accuracy of causal 643 locus identification in time series genome-wide association in sorghum. Plant Physiology 183, 1898-1909.

645

646

647

Miralles DJ, Rharrabti Y, Royo C, Villegas D, Garcia del Moral LF. 2002. Grain setting strategies of Mediterranean durum wheat cultivars released in different periods (1900-2000). Genotype-Phenotype: Narrowing the Gaps. AAB Conference, . Cirencester, UK. Motzo R, Giunta F, Pruneddu G. 2010. The response of rate and duration of grain filling to long-term selection for yield in Italian durum wheats. Crop \& Pasture Science 61, 162-169. Mullan DJ, Reynolds MP. 2010. Quantifying genetic effects of ground cover on soil water evaporation using digital imaging. Functional Plant Biology 37, 703-712. Munir M, Chowdhry MA, Malik TA. 2007. Correlation studies among yield and its components in bread wheat under drought conditions. International Journal of Agriculture and Biology (Pakistan).

Muraya MM, Chu JT, Zhao YS, Junker A, Klukas C, Reif JC, Altmann T. 2017. Genetic variation of growth dynamics in maize (Zea mays L.) revealed through automated non-invasive phenotyping. Plant Journal 89, 366-380.

658 Nofouzi F. 2018. Evaluation of seed yield of durum wheat (Triticum durum) under drought 659 stress and determining correlation among some yield components using path coefficient 660 analysis. Cuadernos de Investigación UNED 10, 179-183.

661 Nuttall JG, O'Leary GJ, Khimashia N, Asseng S, Fitzgerald G, Norton R. 2012. 'Haying-off' in 662 wheat is predicted to increase under a future climate in south-eastern Australia. Crop \& Pasture 663 Science 63, 593-605.

664 Paine CET, Marthews TR, Vogt DR, Purves D, Rees M, Hector A, Turnbull LA. 2012. How to fit nonlinear plant growth models and calculate growth rates: an update for ecologists. Methods in Ecology and Evolution 3, 245-256.

667 Patil RM, Tamhankar SA, Oak MD, Raut AL, Honrao BK, Rao VS, Misra SC. 2013. Mapping 668 of QTL for agronomic traits and kernel characters in durum wheat (Triticum durum Desf.). 669 Euphytica 190, 117-129.

670 Patrignani A, Ochsner TE. 2015. Canopeo: A Powerful New Tool for Measuring Fractional 671 Green Canopy Cover. Agronomy Journal 107, 2312-2320.

672 Peleg Z, Fahima T, Korol AB, Abbo S, Saranga Y. 2011. Genetic analysis of wheat 673 domestication and evolution under domestication. Journal of Experimental Botany 62, 50516745061.

675 Peleg Z, Fahima T, Krugman T, Abbo S, Yakir D, Korol AB, Saranga Y. 2009. Genomic 676 dissection of drought resistance in durum wheat $\mathrm{x}$ wild emmer wheat recombinant inbreed line 677 population. Plant Cell and Environment 32, 758-779. 
678 Pinto RS, Lopes MS, Collins NC, Reynolds MP. 2016. Modelling and genetic dissection of staygreen under heat stress. Theoretical and Applied Genetics 129, 2055-2074.

680 Regan KL, Siddique KHM, Tennant D, Abrecht DG. 1997. Grain yield and water use efficiency of early maturing wheat in low rainfall Mediterranean environments. Australian Journal of

682 Agricultural Research 48, 595-603.

683 Reynolds MP, Pask AJD, Hoppitt WJE, Sonder K, Sukumaran S, Molero G, Saint Pierre C, Payne T, Singh RP, Braun HJ, Gonzalez FG, Terrile, II, Barma NCD, Hakim A, He ZH, Fan ZR, Novoselovic D, Maghraby M, Gad KIM, Galal EG, Hagras A, Mohamed MM, Morad AFA, Kumar U, Singh GP, Naik R, Kalappanavar IK, Biradar S, Prasad SVS, Chatrath R, Sharma I, Panchabhai K, Sohu VS, Mavi GS, Mishra VK, Balasubramaniam A, Jalal-Kamali MR, Khodarahmi M, Dastfal M, Tabib-Ghaffari SM, Jafarby J, Nikzad AR, Moghaddam HA, Ghojogh H, Mehraban A, Solis-Moya E, Camacho-Casas MA, Figueroa-Lopez P, IretaMoreno J, Alvarado-Padilla JI, Borbon-Gracia A, Torres A, Quiche YN, Upadhyay SR, Pandey D, Imtiaz M, Rehman MU, Hussain M, Ud-Din R, Qamar M, Kundi M, Mujahid MY, Ahmad G, Khan AJ, Sial MA, Mustatea P, von Well E, Ncala M, de Groot S, Hussein AHA, Tahir ISA, Idris AAM, Elamein HMM, Manes Y, Joshi AK. 2017. Strategic crossing of biomass and harvest index-source and sink-achieves genetic gains in wheat. Euphytica 213. Rodrigues J, Inze D, Nelissen H, Saibo NJM. 2019. Source-sink regulation in crops under water deficit. Trends in Plant Science 24, 652-663.

697 Royo C, Abaza M, Blanco R, del Moral LFG. 2000. Triticale grain growth and morphometry 698 as affected by drought stress, late sowing and simulated drought stress. Australian Journal of 699 Plant Physiology 27, 1051-1059.

700 Sall AT, Chiari T, Legesse W, Seid-Ahmed K, Ortiz R, van Ginkel M, Bassi FM. 2019. Durum wheat (Triticum durum Desf.): origin, cultivation and potential expansion in Sub-Saharan Africa. Agronomy-Basel 9.

Shavrukov Y, Kurishbayev A, Jatayev S, Shvidchenko V, Zotova L, Koekemoer F, de Groot S, Soole K, Langridge P. 2017. Early flowering as a drought escape mechanism in plants: How can it aid wheat production? Frontiers in Plant Science 8, 1950. Shi SK, Azam FI, Li HH, Chang XP, Li BY, Jing RL. 2017. Mapping QTL for stay-green and agronomic traits in wheat under diverse water regimes. Euphytica 213.

708 Simmonds J, Scott P, Leverington-Waite M, Turner AS, Brinton J, Korzun V, Snape J, Uauy 709 C. 2014. Identification and independent validation of a stable yield and thousand grain weight 710 QTL on chromosome 6A of hexaploid wheat (Triticum aestivum L.). Bmc Plant Biology 14. Smith RCG, Adams J, Stephens DJ, Hick PT. 1995. Forecasting wheat yield in a Mediterranean-type environment from the NOAA satellite. Australian Journal of Agricultural Research 46, 113-125.

Soltani A, Galeshi S. 2002. Importance of rapid canopy closure for wheat production in a temperate sub-humid environment: experimentation and simulation. Field Crops Research 77, 17-30.

Soriano JM, Malosetti M, Rosello M, Sorrells ME, Royo C. 2017. Dissecting the old Mediterranean durum wheat genetic architecture for phenology, biomass and yield formation by association mapping and QTL meta-analysis. Plos One 12. Sun J, Rutkoski JE, Poland JA, Crossa J, Jannink JL, Sorrells ME. 2017. Multitrait, Random Regression, or Simple Repeatability Model in High-Throughput Phenotyping Data Improve Genomic Prediction for Wheat Grain Yield. Plant Genome 10.

723 Teal RK, Tubana B, Girma K, Freeman KW, Arnall DB, Walsh O, Raun WR. 2006. In-season prediction of corn grain yield potential using normalized difference vegetation index. Agronomy Journal 98, 1488-1494. 
Tzarfati R, Barak V, Krugman T, Fahima T, Abbo S, Saranga Y, Korol AB. 2014. Novel quantitative trait loci underlying major domestication traits in tetraploid wheat. Molecular Breeding 34, 1613-1628. Verbyla AP, Cullis BR, Kenward MG, Welham SJ. 1999. The analysis of designed experiments and longitudinal data by using smoothing splines. Journal of the Royal Statistical Society Series C-Applied Statistics 48, 269-300. elongation of durum wheat grown under Mediterranean conditions. Annals of Botany 88, 617627.

735 Vorobiova N, Chernov A. 2017. Curve fitting of MODIS NDVI time series in the task of early crops identification by satellite images. 3rd International Conference Information Technology and Nanotechnology (Itnt-2017) 201, 184-195.

738 Voss-Fels KP, Robinson H, Mudge SR, Richard C, Newman S, Wittkop B, Stahl A, Friedt W, Frisch M, Gabur I, Miller-Cooper A, Campbell BC, Kelly A, Fox G, Christopher J, Christopher M, Chenu K, Franckowiak J, Mace ES, Borrell AK, Eagles H, Jordan DR, Botella JR, Hammer G, Godwin ID, Trevaskis B, Snowdon RJ, Hickey LT. 2018. VERNALIZATION1 Modulates Root System Architecture in Wheat and Barley. Molecular Plant 11, 226-229. Xue JR, Su BF. 2017. Significant remote sensing vegetation indices: a review of developments and applications. Journal of Sensors 2017.

745 Zadoks JC, Chang TT, Konzak CF. 1974. A decimal code for the growth stages of cereals. 746 Weed research 14, 415-421.

747 Zhang JL, Gizaw SA, Bossolini E, Hegarty J, Howell T, Carter AH, Akhunov E, Dubcovsky J. 2018. Identification and validation of QTL for grain yield and plant water status under contrasting water treatments in fall-sown spring wheats. Theoretical and Applied Genetics 131, 1741-1759. 
Table 1. Attributes of the four rainfed yield trials conducted between 2017 and 2020.

\begin{tabular}{|c|c|c|c|c|}
\hline Trial & 2017_RW & 2017_WW & 2019_TS & 2020_WW \\
\hline Location & Roseworthy & Warwick & Tosari & Warwick \\
\hline $\mathrm{SD}^{1}$ & 09/05/2017 & $22 / 06 / 2017$ & 08/07/2019 & $01 / 07 / 2020$ \\
\hline $\operatorname{HarvD}^{2}$ & $22 / 11 / 2017$ & $15 / 11 / 2017$ & $15 / 11 / 2019$ & $26 / 11 / 2020$ \\
\hline No. of plots ${ }^{3}$ & 576 & 336 & 440 & 456 \\
\hline $\mathrm{ICR}(\mathrm{mm})^{4}$ & 320.7 & 137.5 & 12.8 & 185.0 \\
\hline $\operatorname{GDD}\left({ }^{\circ} \mathrm{C}\right)^{5}$ & 2468 & 2190 & 2222 & 2377 \\
\hline Range of $\mathrm{DTF}^{6}$ & $\mathrm{na}^{7}$ & $96-108$ & $84-102$ & $90-104$ \\
\hline Yld $\left(\mathrm{t}-\mathrm{ha}^{-1}\right)^{8}$ & 3.95 & 4.91 & 2.24 & 3.87 \\
\hline No. of geno ${ }^{9}$ & 149 & 147 & 217 & 309 \\
\hline Traits measured & Yld & $\mathrm{SL}^{10}, \mathrm{SN}^{11}, \mathrm{DTF}, \mathrm{Yld}$ & DTF, Yld & $\begin{array}{c}\text { Canopy related traits }{ }^{12} \\
\text { SL, SN, DTF, } \mathrm{PH}^{13} \\
\text { Yld }\end{array}$ \\
\hline
\end{tabular}

${ }^{1}$ Sowing date.

${ }^{2}$ Harvesting date.

${ }^{3}$ Total number of plots in the experiment.

${ }^{4}$ In-crop rainfall.

${ }^{5}$ Growing degree days during growing period.

${ }^{6}$ Range of flowering time of durum NAM population grown in the experiment, expressed as days to flowering.

${ }^{7}$ Data is not available.

${ }^{8}$ Mean yield of all genotypic BLUEs.

${ }^{9}$ Number of durum NAM lines and parents.

${ }^{10}$ Spike length measured in $\mathrm{cm}$.

${ }^{11}$ Spike number per unit area.

${ }^{12}$ Canopy related traits include NDVI, and fractional green canopy cover at multiple time points at population level, and tiller number measured on 11 selected genotypes. 
${ }^{13}$ Plant height measured in $\mathrm{cm}$.

Table 2. Description of durum wheat genotypes in the 2020 field trial, including the 10 NAM parents and subset of 299 NAM lines

\begin{tabular}{|c|c|c|}
\hline NAM Parent & Pedigree & No. of rep \\
\hline Fastoz2 & T.polonicumTurkeyIG45272/6/ICAMORTA0463/5/Mra1/4/Aus1/3/Scar/GdoVZ579//Bit & 2 \\
\hline Fastoz3 & Msbl1//Awl2/Bit/3/T.dicoccoidesSYRIG117887 & 5 \\
\hline Fastoz6 & Azeghar1/6/Zna1/5/Aw11/4/Ruff//Jo/Cr/3/F9.3/7/Azeghar1//Msbl1/Quarmal & 2 \\
\hline Fastoz7 & CandocrossH25/Ysf1//CM829/CandocrossH25 & 2 \\
\hline Fastoz8 & MorlF38//Bcrch1/Kund1149/3/Bicrederaa1/Miki = Kunmiki & 3 \\
\hline Fastoz10 & Younes $/$ TdicoAlpCol//Korifla $=$ Trouve & 1 \\
\hline Fadda98 & Awl2/Bit $=$ Awalbit 9 & 5 \\
\hline DBA Aurora & Tamaroi*2/Kalka//RH920318/Kalka///Kalka*2/Tamaroi & 3 \\
\hline Jandaroi & $110780 / 111587$ & 1 \\
\hline Outrob4 & Ouassel-1/4/GdoVZ 512/Cit//Ruff/Fg/3/Pin/Gre//Trob = Fadda98 & 1 \\
\hline NAM family & $\begin{array}{l}\text { Pedigree } \\
\end{array}$ & No. of geno \\
\hline 1 & DBA Aurora/Fastoz7 & 20 \\
\hline 2 & DBA Aurora/Outrob4 & 74 \\
\hline 3 & DBA Aurora/Fastoz8 & 80 \\
\hline 5 & DBA Aurora/Fastoz3 & 80 \\
\hline 6 & Jandaroi/Fastoz8 & 16 \\
\hline 10 & Jandaroi/Outrob4 & 29 \\
\hline
\end{tabular}


Table 3. Summary statistics for traits studied in the 2020 field trial, including minimum (Min), mean, maximum (Max), and coefficient of variation (CV) for trait BLUEs.

\begin{tabular}{|c|c|c|c|c|}
\hline Traits & Min & Mean & Max & CV (\%) \\
\hline NDVI_22DAS $^{1}$ & 0.22 & 0.27 & 0.33 & 6.3 \\
\hline NDVI_29DAS & 0.23 & 0.33 & 0.4 & 9.3 \\
\hline NDVI_36DAS & 0.26 & 0.45 & 0.55 & 9.6 \\
\hline NDVI_43DAS & 0.39 & 0.63 & 0.74 & 7.9 \\
\hline NDVI_50DAS & 0.67 & 0.84 & 0.88 & 3.5 \\
\hline NDVI_63DAS & 0.82 & 0.88 & 0.9 & 1.3 \\
\hline NDVI_70DAS & 0.87 & 0.89 & 0.91 & 0.6 \\
\hline NDVI_78DAS & 0.88 & 0.9 & 0.91 & 0.5 \\
\hline FGCC_-29DAS ${ }^{2}$ & 3.21 & 10.35 & 16.52 & 17.1 \\
\hline FGCC_36DAS & 7.6 & 23.34 & 33.67 & 16.9 \\
\hline FGCC_43DAS & 20.63 & 44.01 & 57.51 & 13.5 \\
\hline FGCC_50DAS & 39.81 & 70.86 & 83.91 & 9.9 \\
\hline AUC_SS ${ }^{3}$ & 3.77 & 5.6 & 7.08 & 7.4 \\
\hline AUC_TL ${ }^{4}$ & 14.83 & 20 & 21.8 & 5 \\
\hline AUC_SE ${ }^{5}$ & 15.47 & 15.98 & 16.32 & 0.7 \\
\hline $\mathrm{AUC}_{-} \mathrm{VS}^{6}$ & 34.99 & 41.57 & 44.46 & 3.4 \\
\hline $\mathrm{PH}(\mathrm{cm})$ & 58 & 77 & 94 & 7.9 \\
\hline DTF (days) & 90 & 95 & 104 & 2.1 \\
\hline $\mathrm{SL}(\mathrm{cm})$ & 7.19 & 9.21 & 11.35 & 8.3 \\
\hline $\mathrm{SN}\left(-\mathrm{m}^{-2}\right)$ & 115 & 248 & 365 & 17.7 \\
\hline Yld $\left(\mathrm{t}-\mathrm{ha}^{-1}\right)$ & 1.66 & 3.63 & 5.56 & 17.8 \\
\hline
\end{tabular}

${ }^{1}$ Normalized difference vegetation index (NDVI) measured at 22 days after sowing (DAS).

${ }^{2}$ Fractional green canopy cover (FGCC) measured at 29 DAS.

${ }^{3}$ Area under the curve of smoothed time-series NDVI (AUC) between 0-30 DAS.

${ }^{4}$ AUC between 30-60 DAS.

${ }^{5}$ AUC between 60-78 DAS. 
${ }^{6}$ AUC between 0 and 78 DAS.

Table 4. Summary of results from association mapping of canopy development and other traits in the 2020 field trial (2020_WW).

\begin{tabular}{|c|c|c|c|c|c|c|c|c|}
\hline Trait & SNP & Positive allele & Chr $^{1}$ & $\mathbf{M A F}^{2}$ & Pos.St (bp) ${ }^{3}$ & Pos.End (bp) ${ }^{4}$ & $-\log 10(p)^{5}$ & $-\log 10(p-\text { FDR })^{6}$ \\
\hline \multirow{6}{*}{ NDVI_29DAS } & 1271404 & 1 & $2 \mathrm{~A}$ & 0.21 & 745108704 & 745108769 & 6.15 & 2.44 \\
\hline & 3023448 & 1 & $3 \mathrm{~A}$ & 0.49 & 41109698 & 41109735 & 4.80 & 1.78 \\
\hline & 5324123 & 1 & $4 \mathrm{~A}$ & 0.13 & 642498972 & 642499004 & 4.33 & 1.39 \\
\hline & 1202152 & 0 & $4 B$ & 0.49 & 565602357 & 565602424 & 5.72 & 2.31 \\
\hline & 4404447 & 1 & $6 \mathrm{~A}$ & 0.35 & 12144868 & 12144909 & 4.97 & 1.85 \\
\hline & 1127685 & 0 & $6 \mathrm{~B}$ & 0.22 & 135162876 & 135162808 & 5.09 & 1.85 \\
\hline \multirow{2}{*}{ NDVI_36DAS } & 977411 & 1 & $4 \mathrm{~A}$ & 0.21 & 695150339 & 695150395 & 5.45 & 2.03 \\
\hline & 1130263 & 0 & $5 \mathrm{~A}$ & 0.06 & 417840038 & 417840097 & 7.77 & 4.05 \\
\hline NDVI_43DAS & 1271404 & 1 & $2 \mathrm{~A}$ & 0.21 & 745108704 & 745108769 & 5.97 & 2.25 \\
\hline \multirow{3}{*}{ NDVI_50DAS } & 2256343 & 1 & $2 \mathrm{~A}$ & 0.11 & 36364366 & 36364298 & 5.98 & 2.57 \\
\hline & 1271404 & 1 & $2 \mathrm{~A}$ & 0.21 & 745108704 & 745108769 & 6.34 & 2.63 \\
\hline & 3949783 & 0 & $2 \mathrm{~B}$ & 0.28 & 697623388 & 697623452 & 4.71 & 1.47 \\
\hline NDVI_70DAS & 996714 & 1 & $7 \mathrm{~A}$ & 0.17 & 109908919 & 109908968 & 5.71 & 2.00 \\
\hline \multirow{4}{*}{ AUC_SS } & 4004899 & 1 & $2 \mathrm{~A}$ & 0.35 & 735922887 & 735922955 & 4.47 & 1.35 \\
\hline & 1095539 & 1 & $2 \mathrm{~B}$ & 0.29 & 618076302 & 618076370 & 7.17 & 3.45 \\
\hline & 3946360 & 1 & $4 \mathrm{~A}$ & 0.19 & 24099524 & 24099564 & 5.46 & 2.22 \\
\hline & 1093322 & 0 & $5 B$ & 0.20 & 528696884 & 528696822 & 5.91 & 2.49 \\
\hline AUC_TL & 1271404 & 1 & $2 \mathrm{~A}$ & 0.21 & 745108704 & 745108769 & 5.48 & 1.76 \\
\hline \multirow{4}{*}{ AUC_SE } & 4004899 & 1 & $2 \mathrm{~A}$ & 0.35 & 735922887 & 735922955 & 4.47 & 1.35 \\
\hline & 1095539 & 0 & $2 \mathrm{~B}$ & 0.29 & 618076302 & 618076370 & 7.17 & 3.45 \\
\hline & 3946360 & 1 & $4 \mathrm{~A}$ & 0.19 & 24099524 & 24099564 & 5.46 & 2.22 \\
\hline & 1093322 & 0 & $5 \mathrm{~B}$ & 0.20 & 528696884 & 528696822 & 5.91 & 2.49 \\
\hline
\end{tabular}




\begin{tabular}{|c|c|c|c|c|c|c|c|c|}
\hline \multirow{2}{*}{ AUC_VS } & 1271404 & 1 & $2 \mathrm{~A}$ & 0.21 & 745108704 & 745108769 & 5.82 & 2.31 \\
\hline & 1108975 & 0 & $2 \mathrm{~B}$ & 0.07 & 55930502 & 55930570 & 5.73 & 2.31 \\
\hline DTF & 2256343 & 0 & $2 \mathrm{~A}$ & 0.11 & 36364298 & 36364366 & 17.50 & 13.78 \\
\hline \multirow{6}{*}{$\mathrm{PH}$} & 4009205 & 0 & $2 \mathrm{~A}$ & 0.27 & 982116 & 982183 & 4.73 & 1.54 \\
\hline & 1698984 & 1 & $2 \mathrm{~A}$ & 0.22 & 131154183 & 131154248 & 4.50 & 1.54 \\
\hline & 1017668 & 1 & $2 \mathrm{~A}$ & 0.17 & 695473023 & 695473091 & 4.50 & 1.54 \\
\hline & 1088708 & 1 & $4 \mathrm{~B}$ & 0.50 & 637884852 & 637884784 & 5.30 & 1.58 \\
\hline & 3064427 & 1 & $5 B$ & 0.18 & 533724323 & 533724367 & 4.80 & 1.54 \\
\hline & 5411254 & 0 & $7 \mathrm{~A}$ & 0.20 & 32647340 & 32647399 & 4.48 & 1.54 \\
\hline \multirow{7}{*}{ SL } & 1215020 & 0 & $1 \mathrm{~B}$ & 0.47 & 640187467 & 640187527 & 4.65 & 1.78 \\
\hline & 4992547 & 0 & $3 \mathrm{~A}$ & 0.22 & 618058814 & 618058882 & 5.86 & 2.75 \\
\hline & 1091678 & 1 & $4 \mathrm{~A}$ & 0.46 & 636321605 & 636321665 & 8.84 & 5.13 \\
\hline & 3954609 & 0 & $4 \mathrm{~A}$ & 0.12 & 190565472 & 190565511 & 4.67 & 1.78 \\
\hline & 1055097 & 0 & $5 \mathrm{~A}$ & 0.09 & 639650884 & 639650944 & 6.51 & 3.27 \\
\hline & 982085 & 0 & $5 \mathrm{~A}$ & 0.46 & 43161899 & 43161953 & 4.79 & 1.78 \\
\hline & 1092206 & 1 & $6 \mathrm{~A}$ & 0.39 & 543489106 & 543489174 & 7.16 & 3.75 \\
\hline
\end{tabular}

${ }^{1}$ Chromosome.

${ }^{2}$ Minor allele frequency.

${ }^{3}$ The start of the SNP position on the 'Svevo' durum reference genome.

${ }^{4}$ The end of the SNP position on the 'Svevo' durum reference genome.

${ }^{5}-\log 10$ of uncorrected $p$ value of marker-trait association.

${ }^{6}-\log 10$ of FDR adjusted $p$ value.

Table 5. Summary of marker $\times$ environment interactions for yield. Predicted means of yield are presented for allele 0 and 1 at each SNP locus, and each SNP allele $\times$ trial combination. Significant differences are indicated by different letters at 0.01 probability level following Tukey's test.

\begin{tabular}{cccccccccc} 
Chromosome & 2A & 2A & 2B & 2B & 2B & 3A & 4A & 6A & 6B \\
\hline Allele & 1271404 & 4004899 & 1108975 & 1095539 & 3949783 & 3023448 & 5324123 & 4404447 & 1127685 \\
\hline
\end{tabular}




\begin{tabular}{|c|c|c|c|c|c|c|c|c|c|c|c|}
\hline \multirow{2}{*}{ SNP } & & 0 & 3.24 & 3.65 & 3.69 & 3.63 & 3.63 & 3.62 & 3.7 & 3.7 & 3.68 \\
\hline & & 1 & 3.77 & 3.7 & 3.66 & 3.76 & 3.77 & 3.64 & 3.58 & 3.5 & 3.66 \\
\hline \multirow{8}{*}{$\mathrm{SNP} \times \mathrm{Env}$} & \multirow{2}{*}{ 2017_RW } & 0 & $3.43 b$ & $3.94 \mathrm{c}$ & $4 c$ & $3.84 b c$ & $3.85 \mathrm{~cd}$ & $4.02 \mathrm{c}$ & $3.93 d$ & $4.03 c$ & $4.00 \mathrm{c}$ \\
\hline & & 1 & $4.00 \mathrm{~b}$ & $3.95 \mathrm{c}$ & $3.55 \mathrm{abcd}$ & $4.07 \mathrm{c}$ & $4.08 \mathrm{~d}$ & $3.80 \mathrm{bc}$ & $3.98 \mathrm{~d}$ & $3.61 \mathrm{~b}$ & $3.76 b c$ \\
\hline & \multirow{2}{*}{ 2017_WW } & 0 & $4.5 \mathrm{bc}$ & $4.95 \mathrm{~d}$ & $4.91 d$ & $4.70 \mathrm{~d}$ & $4.71 \mathrm{e}$ & $4.81 \mathrm{~d}$ & $4.96 \mathrm{e}$ & $4.98 \mathrm{~d}$ & $4.88 \mathrm{~d}$ \\
\hline & & 1 & $5.11 \mathrm{c}$ & $4.9 \mathrm{~d}$ & $4.67 \mathrm{bcd}$ & $5.16 \mathrm{e}$ & $5.16 \mathrm{f}$ & $4.86 \mathrm{~d}$ & $4.83 \mathrm{e}$ & $4.58 \mathrm{~d}$ & $5.05 \mathrm{~d}$ \\
\hline & \multirow{2}{*}{ 2019_TS } & 0 & $1.86 \mathrm{a}$ & $2.22 \mathrm{a}$ & $2.27 \mathrm{a}$ & $2.26 \mathrm{a}$ & $2.26 \mathrm{a}$ & $2.25 \mathrm{a}$ & $2.20 \mathrm{a}$ & $2.26 a$ & $2.26 \mathrm{a}$ \\
\hline & & 1 & $2.22 \mathrm{a}$ & $2.25 \mathrm{a}$ & $2.45 \mathrm{abc}$ & $2.22 \mathrm{a}$ & $2.22 \mathrm{a}$ & $2.22 \mathrm{a}$ & $2.35 \mathrm{a}$ & $2.05 \mathrm{a}$ & $2.11 \mathrm{a}$ \\
\hline & \multirow{2}{*}{ 2020_WW } & 0 & $3.19 b$ & $3.49 b$ & $3.57 b$ & $3.70 \mathrm{~b}$ & $3.72 b c$ & $3.40 \mathrm{~b}$ & $3.69 \mathrm{c}$ & $3.54 b$ & $3.60 \mathrm{~b}$ \\
\hline & & 1 & $3.74 b$ & $3.69 \mathrm{bc}$ & $3.98 \mathrm{bcd}$ & $3.60 \mathrm{~b}$ & $3.59 \mathrm{~b}$ & $3.68 \mathrm{bc}$ & $3.16 \mathrm{~b}$ & $3.76 \mathrm{~b}$ & $3.74 b c$ \\
\hline \multirow{2}{*}{$p$-value } & \multicolumn{2}{|c|}{ Main effect } & $1.36 \mathrm{e}-05$ & 0.1 & 0.66 & 0.22 & 0.28 & 0.13 & 0.07 & 0.52 & 0.93 \\
\hline & \multicolumn{2}{|c|}{$M \times E$ effect } & 0.02 & 0.04 & $4.39 \mathrm{e}-09$ & $8.64 \mathrm{e}-06$ & $8.93 \mathrm{e}-06$ & 0.01 & $4.47 \mathrm{e}-06$ & $1.22 \mathrm{e}-08$ & 0.002 \\
\hline
\end{tabular}

Table 6. Comparison of two homozygous alleles at four SNP loci for spike traits measured in 2017_WW and 2020_WW. Data was analysed with unpaired t-test in two trials separately.

\begin{tabular}{|c|c|c|c|c|c|c|c|c|}
\hline SNP & Chr & Trial & Allele & $\mathrm{N}^{1}$ & Mean_SL ${ }^{2}$ & $p$-value_SL & Mean_SN ${ }^{3}$ & $p$-value_SN \\
\hline \multirow{4}{*}{1095539} & \multirow{4}{*}{$2 \mathrm{~B}$} & \multirow{2}{*}{ 2017_WW } & 0 & 80 & 7.29 & \multirow{2}{*}{$<0.05$} & 323 & \multirow{2}{*}{0.16} \\
\hline & & & 1 & 66 & 7.52 & & 311 & \\
\hline & & \multirow{2}{*}{ 2020_WW } & 0 & 89 & 8.98 & \multirow{2}{*}{$<0.001$} & 254 & \multirow{2}{*}{0.11} \\
\hline & & & 1 & 218 & 9.3 & & 245 & \\
\hline \multirow{4}{*}{3949783} & \multirow{4}{*}{$2 \mathrm{~B}$} & \multirow{2}{*}{ 2017_WW } & 0 & 80 & 7.35 & \multirow{2}{*}{0.35} & 321 & \multirow{2}{*}{0.40} \\
\hline & & & 1 & 66 & 7.46 & & 314 & \\
\hline & & \multirow{2}{*}{ 2020_WW } & 0 & 84 & 8.99 & \multirow{2}{*}{$<0.001$} & 248 & \multirow{2}{*}{0.94} \\
\hline & & & 1 & 223 & 9.31 & & 248 & \\
\hline \multirow{2}{*}{5324123} & \multirow{2}{*}{$4 \mathrm{~A}$} & \multirow{2}{*}{ 2017_WW } & 0 & 92 & 7.44 & \multirow{2}{*}{0.44} & 311 & \multirow{2}{*}{$<0.05$} \\
\hline & & & 1 & 50 & 7.34 & & 330 & \\
\hline
\end{tabular}




\begin{tabular}{|c|c|c|c|c|c|c|c|c|}
\hline & \multirow[b]{2}{*}{ 2020_WW } & & & & \multirow[b]{2}{*}{$<0.001$} & & \multirow[b]{2}{*}{$<0.01$} \\
\hline & & & $\begin{array}{l}0 \\
1\end{array}$ & $\begin{array}{c}256 \\
36 \\
\end{array}$ & $\begin{array}{l}9.27 \\
8.82\end{array}$ & & $\begin{array}{l}245 \\
268 \\
\end{array}$ & \\
\hline \multirow{2}{*}{4404447} & \multirow{2}{*}{$6 \mathrm{~A}$} & 2017_WW & $\begin{array}{l}0 \\
1 \\
\end{array}$ & $\begin{array}{c}122 \\
25 \\
\end{array}$ & $\begin{array}{l}7.39 \\
7.46 \\
\end{array}$ & 0.37 & $\begin{array}{l}321 \\
304 \\
\end{array}$ & 0.12 \\
\hline & & 2020_WW & $\begin{array}{l}0 \\
1\end{array}$ & $\begin{array}{l}200 \\
109\end{array}$ & $\begin{array}{l}9.18 \\
9.28\end{array}$ & 0.28 & $\begin{array}{l}250 \\
244\end{array}$ & 0.27 \\
\hline
\end{tabular}

${ }^{1}$ Number of individuals carrying allele 0 or 1 of a given SNP within the trial.

${ }^{2}$ Mean spike length (cm).

${ }^{3}$ Mean spike number per $\mathrm{m}^{2}$. 


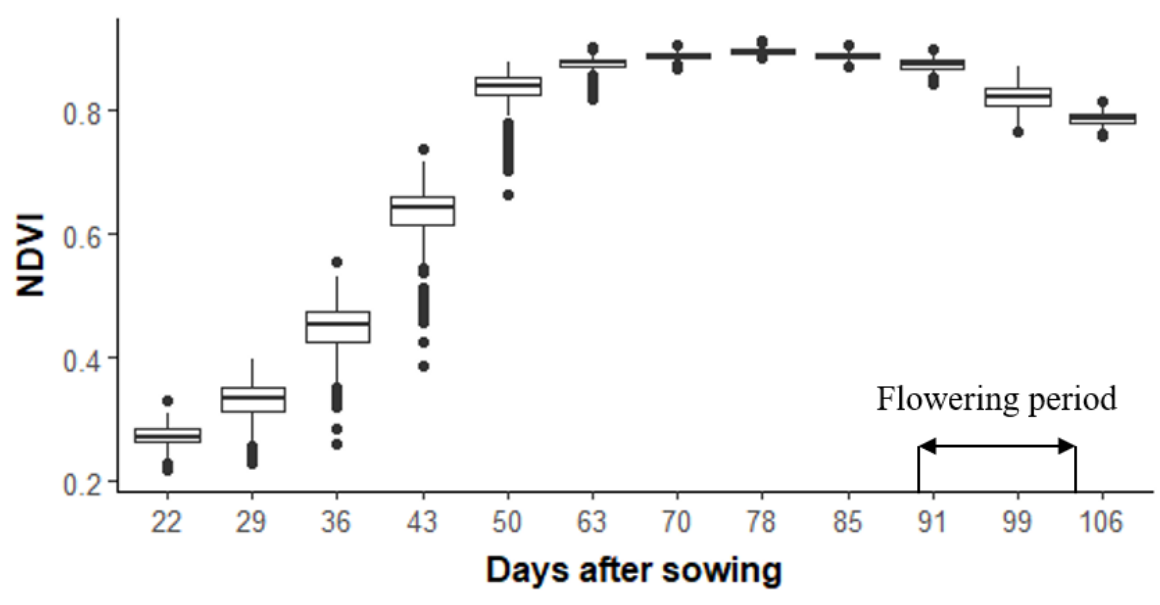

Fig. 1. Variability of normalized difference vegetation index (NDVI) of the durum nestedassociation mapping population in 2020_WW. Each boxplot represents the range of best linear unbiased estimates (BLUEs) for NDVI at each time-point.

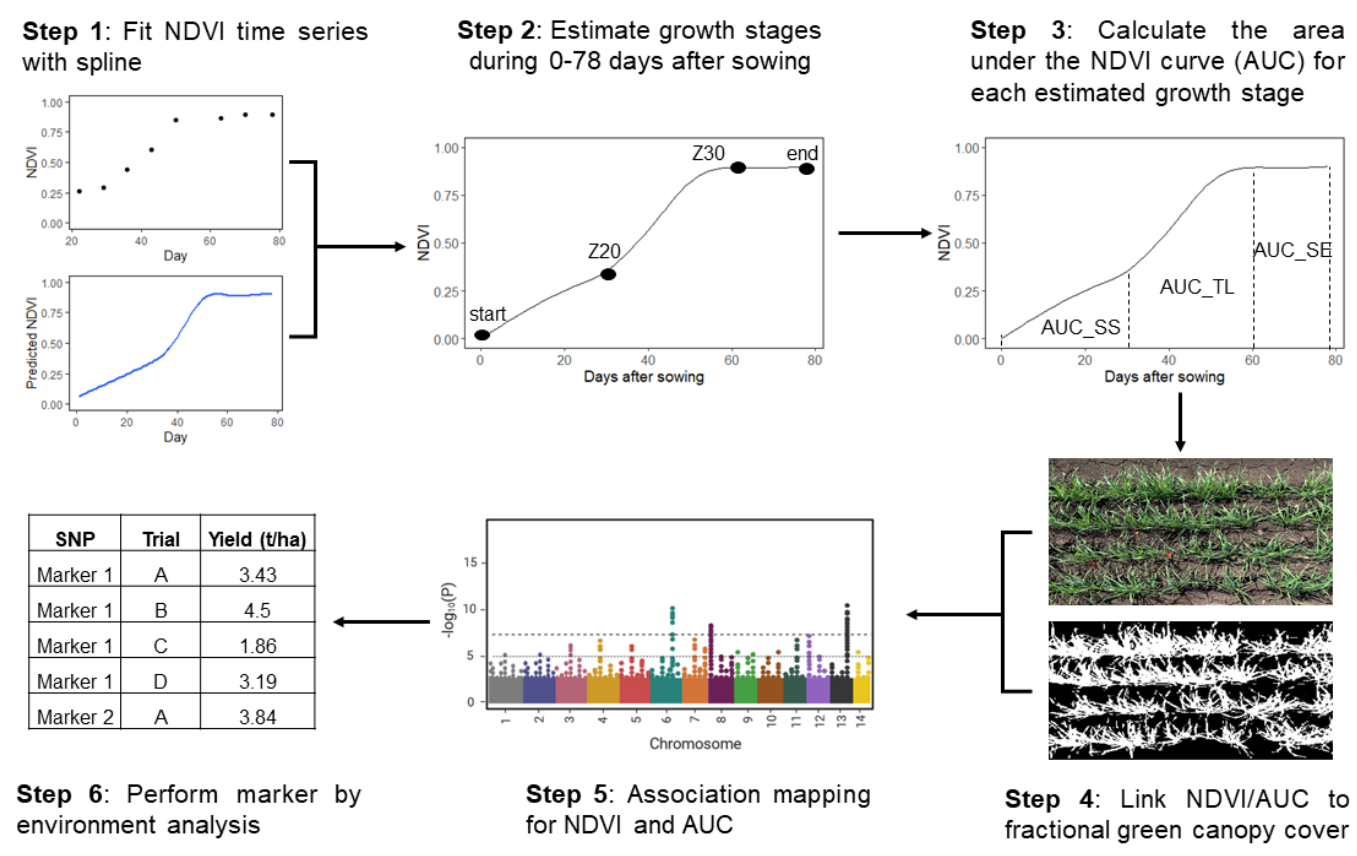

Fig. 2. Experimental analyses performed in this study involved the fitting of NDVI time series with a spline (1), estimation of growth stages (2), calculation of AUC for NDVI (3), link of NDVI/AUC to fractional green canopy cover (4), association mapping (5) and marker by environment analysis (6). 


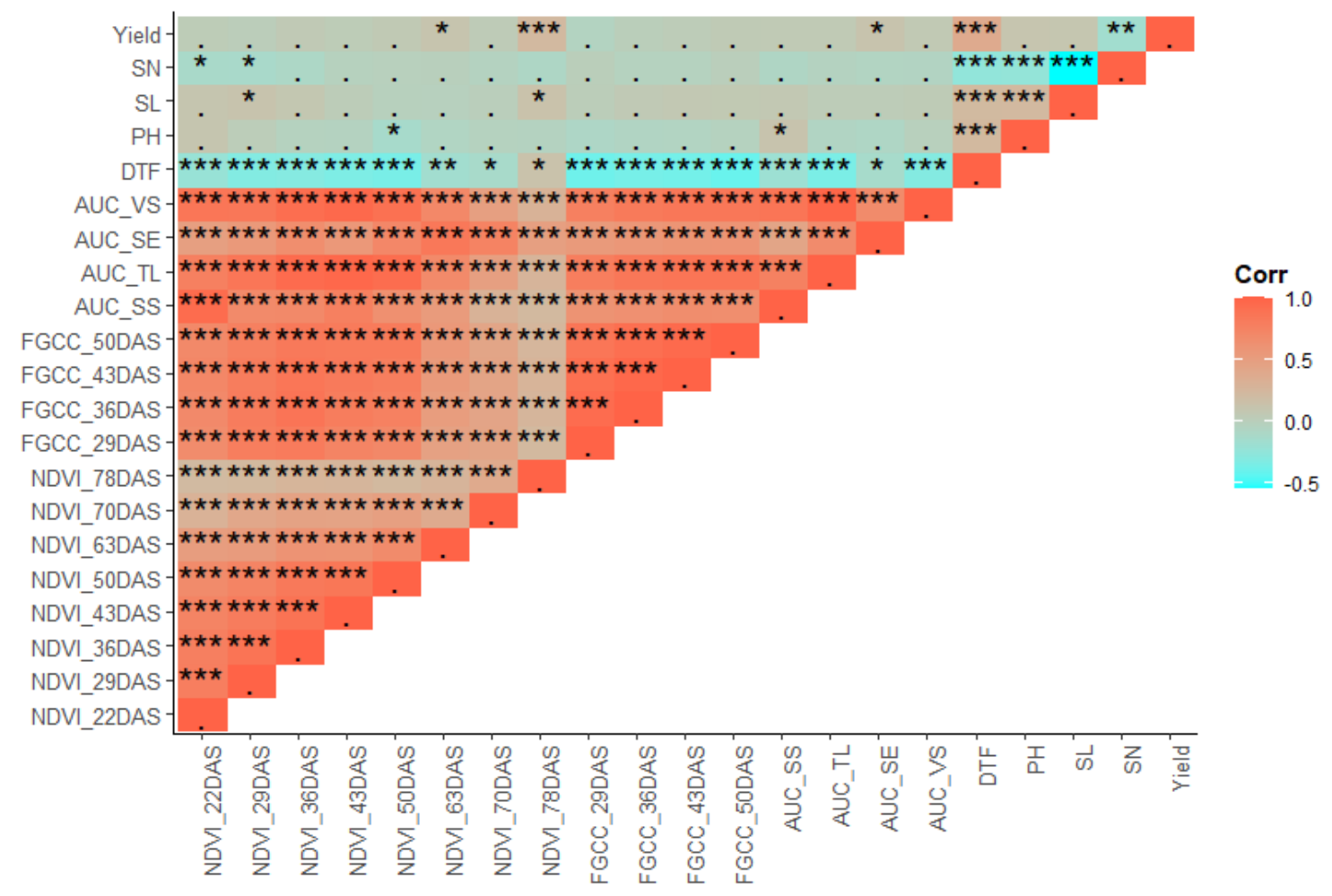

Fig. 3. Heatmap of trait by trait correlations in the 2020_WW trial. Pearson's correlation was computed for each pair of traits. The colour key represents the Pearson's correlation coefficient. Level of significance $*: p<0.05$; **: $p<0.01$; ***: $p<0.001$. The explanation for trait abbreviation can be found in Table 3 .

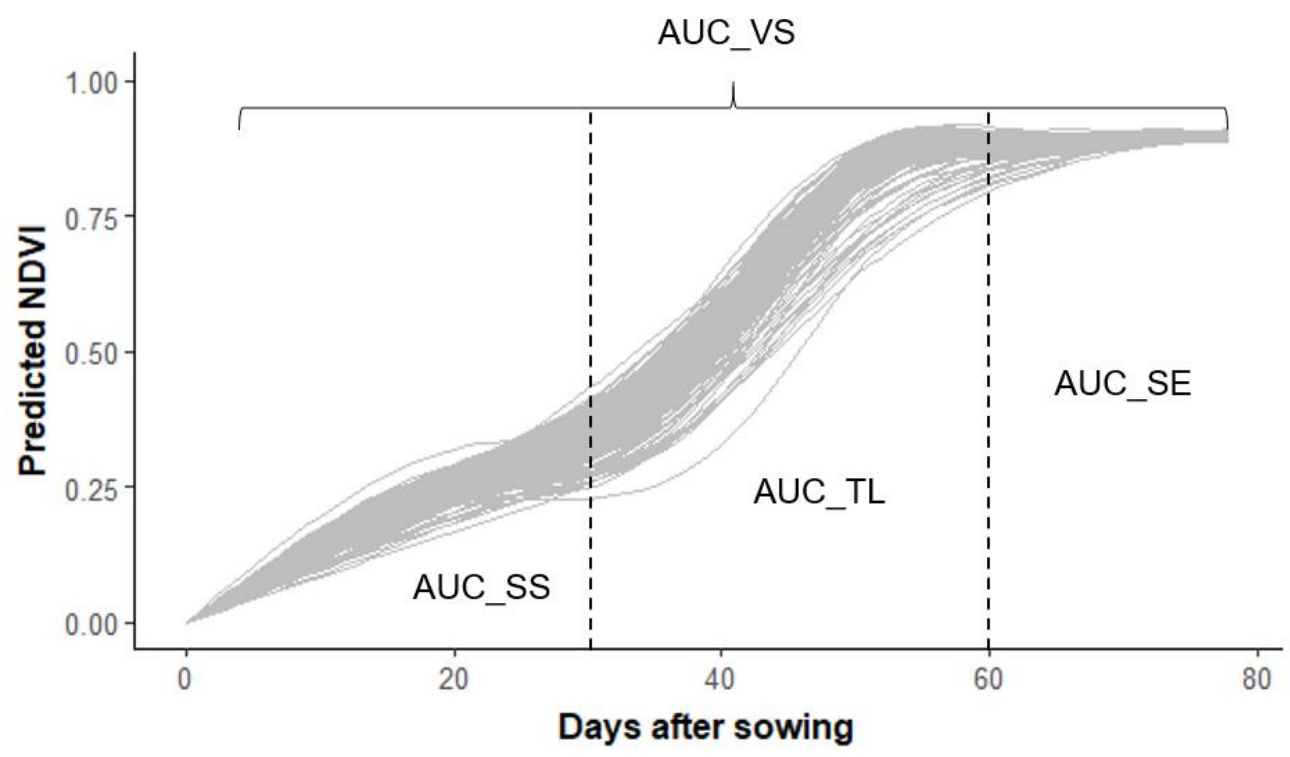


Fig. 4. Trajectories of time-series NDVI of all genotypes in the mapping population fitted with smoothing splines. The breakpoints 30 and 60 days after sowing were used to bin the whole range of simulated NDVI data. First phase = seedling stage (AUC_SS, 0-30 DAS), second phase $=$ tillering $($ AUC_TL, 30-60 DAS $)$, third phase $=$ stem elongation $($ AUC_SE, 60-78 DAS).

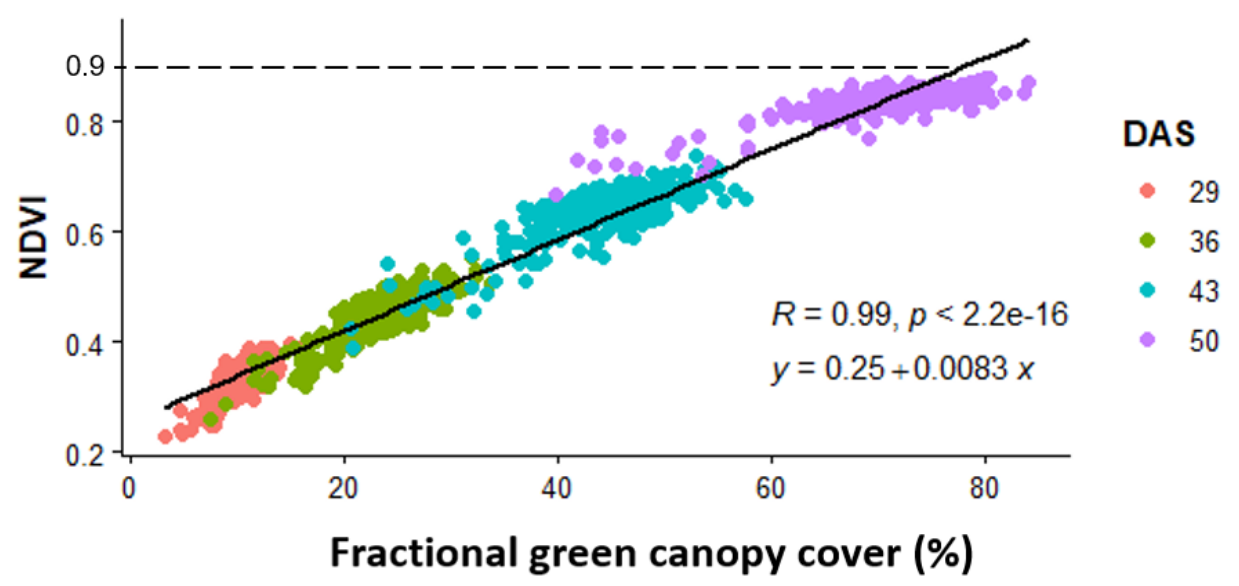

Fig. 5. Relationship between BLUEs of NDVI and fractional green canopy cover measured at 29, 36, 43 and 50 DAS. 